\title{
VIII
}

\section{A IDEOLOGIA BURGUESA NA CONFORMAÇÃO DA UNIVERSIDADE PÚBLICA NO BRASIL*}

\author{
Priscila Keiko C. Sakurada
}

\section{INTRODUÇÃO}

A partir dos estudos realizados por Florestan Fernandes, as classes sociais que se constituem na formação social brasileira não se caracterizam pelos moldes clássicos, tal como se observa nos países onde a revolução burguesa operou uma ruptura contundente com as formas sociais anteriores, na busca por autonomia, instituindo novas formas de organização do modo de produção e reprodução das classes e da nação.

Conforme Fernandes (2005), a formação social brasileira é marcada pela não ruptura com o seu lastro de dependência colonial, em que, permanece até os dias atuais, a concentração de poder, renda e prestígio herdada dos senhores rurais-latifundiários e escravagistas, conforme analisado nos capítulos anteriores. Estes elementos, no percurso da história, acentuaram as desigualdades estruturais, caracterizando, inclusive, não uma classe burguesa homogênea, mas frações da classe burguesa, que não romperam a dependência com o capitalismo internacional, mas a aprofundaram, agravando assim, a segregação entre as classes sociais. Ou seja, não se trata de um desenvolvimento econômico que visa enfrentar os problemas fundamentais que estruturam e dinamizam a sociedade brasileira, mas um crescimento econômico dependente que objetiva apenas atender os interesses mercantis das frações burguesas, ainda que isto signifique renunciar à soberania nacional.

Assim, neste capítulo buscaremos entender como a particularidade do capitalismo dependente no Brasil produz e reproduz, nos espaços da Universidade Pública, a ideologia do prestígio, poder e concentração de renda enquanto elementos estruturantes e dinâmicos das frações burguesas dominantes.

Isso porque, para impor uma "[...] alienação de mediações de segunda ordem” (MÉSZÁROS, 2008, p. 72), onde as frações dominantes consigam interiorizar nos sujeitos singulares os "[...] valores, normas, juízos e comportamen- 
tos a partir das relações imediatas" (IASI, 2011, p. 28) de sua visão de mundo e as justificar ideologicamente nas relações sociais, mais do que dominar a força material, é necessário também que ocorra a dominação dos meios de produção e a reprodução espiritual (MARX; ENGELS, 2007).

Desta feita, quando dizemos que esta ideologia se expressa e se reproduz nos espaços da Universidade Pública, estamos trabalhando com o entendimento de que, na sociedade capitalista dependente, a Universidade expressará e produzirá as contradições concretas e as mediações específicas das disputas entre projetos sociais antagônicos em curso, não sendo possível analisá-la, portanto, descolada dos "[...] processos educacionais e [d]os processos sociais mais abrangentes de reprodução" (MÉSZÁROS, 2008, p. 12).

Com o objetivo de organizar de forma didática as reflexões que realizamos, a partir da interlocução com a obra florestaniana, no primeiro item deste capítulo trataremos sobre o que denominamos como ideologia do prestígio, poder e renda, que caracteriza a particularidade da formação social brasileira. No segundo item, abordaremos como esta ideologia incide nos espaços da Universidade Pública, gestando disputas entre projetos educacionais que, em última instância, expressam a luta das classes sociais no Brasil. Por fim, teceremos algumas considerações sobre as lutas que nos aguardam em defesa da Universidade Pública.

\section{IDEOLOGIA DO PRESTÍGIO, PODER E CONCENTRAÇÃo DE RENDA NA FORMAÇÃO SOCIAL BRASILEIRA}

Para que possamos analisar a forma como a ideologia se expressa nas relações sociais capitalistas dependentes, particularmente na sociedade brasileira, é necessário demarcarmos sobre qual perspectiva teórica estamos trabalhando o conceito de ideologia ${ }^{1}$. Ao longo do século XIX até a atualidade, diversos autores têm se debruçado para estudar e realizar a crítica ao conceito de ideologia, demonstrando que "[...] o surgimento do conceito de ideologia não é um mero capítulo na história das ideias. Ao contrário, está intimamente relacionado com a luta revolucionária e figura, desde o início, como uma arma teórica da guerra de classes" (EAGLETON, 2019, p. 85).

\footnotetext{
${ }^{1}$ Conforme Williams (2007) o termo ideologia foi cunhado pelo filósofo racionalista Antoine Destutt de Tracy, e significava originalmente uma ciência das ideias, que buscava distinguir-se da metafísica. Em ataques impetrados por Napoleão Bonaparte aos princípios iluministas e aos seus oponentes, o termo ideologia passa a ter um sentido diferente do que se iniciou e se populariza como sendo "uma teoria abstrata, não prática ou fanática" (WILLIAMS, 2007, p. 213).
} 
Partindo do pressuposto que "[...] não existe pensamento que não seja socialmente determinado" (EAGLETON, 2019, p. 67), e, portanto, determinado pela realidade concreta e material, o que buscaremos analisar é como "[...] o complexo conjunto de ligações ou mediações entre seus níveis mais ou menos articulados" (EAGLETON, 2019, p. 66) das particularidades da formação social brasileira produzirá e reproduzirá uma determinada dinâmica nas relações sociais, nas suas instituições e nas classes sociais.

Neste bojo, partimos do entendimento de que o capitalismo se caracteriza enquanto sistema econômico-político que opera, tanto na esfera de produção, quanto de reprodução, uma dinâmica distinta e específica de divisão do trabalho, propriedade privada dos meios de produção e de classes sociais. Conforme Marx (2008b; 2010; 2015), não apenas o produto do trabalho converte-se em mercadoria, mas, todas as esferas da vida social tornam-se mercantis, impulsionadas pelo equivalente universal das mercadorias, a moeda, ocasionando uma valorização do mundo das coisas e uma desvalorização do mundo dos homens.

Denominada por Marx (2010) como estranhamento, o modo de vida que é estabelecido no capitalismo afasta qualquer possibilidade do homem entender que se trata de uma atividade socialmente produzida entre homens na vida coletiva. Assim, ao intercambiar essa atividade por meio do dinheiro, expressando a forma alienada do seu valor de troca, as relações passam a ser concebidas como atividades entre coisas e não mais como constitutivas do trabalho socialmente produzido pelos homens, velando as possibilidades do indivíduo se reconhecer enquanto um ser universal que também é singular na produção e reprodução social (MARX, 2008, 2010).

Isso tem implicações diretas na própria compreensão do gênero humano, enquanto determinante da constituição e do grau de desenvolvimento científico e histórico da humanidade, bem como seus processos contraditórios de reprodução na atualidade. Pois,

O modo pelo qual os homens produzem seus meios de vida depende, antes de tudo, da própria constituição dos meios de vida já encontrados e que eles têm de reproduzir. Esse modo de produção não deve ser considerado meramente sob o aspecto de ser a reprodução da existência física dos indivíduos. Ele é, muito mais, uma forma determinada de sua atividade, uma forma determinada de exteriorizar sua vida, um determinado modo de vida desses indivíduos. Tal como os indivíduos exteriorizam a vida, assim são eles. O que eles são coincide, pois, com sua produção, tanto com o que produzem como também com o modo como produ- 
zem. O que os indivíduos são, portanto, depende das condições materiais de sua produção (MARX; ENGELS, 2007, p. 87).

Acrescenta-se à existência de meios de vida já encontrados o fato de que:

Os homens fazem sua própria história, mas não a fazem como querem; não a fazem sob circunstâncias de sua escolha e sim sob aquelas com quem se defrontam diretamente, legadas e transmitidas pelo passado (MARX, 2008b, p, 19).

Desta feita, na relação mercantil capitalista, ao converter a exterioridade em uma mera utilidade que pode ser apropriada privadamente, o que percebemos é que o homem se torna objetivo para si, ao mesmo tempo em que se torna um objeto estranho e inumano, perdendo-se o domínio da efetividade humana (MARX, 2010).

Ou seja, a objetivação estranhada aparece enquanto uma coisa/objeto de existência externa, "[...] que existe fora dele [trabalhador], independente dele e estranha a ele, tornando-se uma potência autônoma diante dele e estranha a ele, que a vida que ele concedeu ao objeto se lhe defronta hostil e estranha" (MARX, 2008, p. 81).

O que ocorre no modo de produção capitalista é que, dado o seu cará ter contraditório forjado pela apropriação privada de uma classe sobre a outra, reproduzindo uma exteriorização estranhada, a ruptura entre o agir e o pensar, comparecendo, também, dentro da própria classe dominante. Tem-se, assim, uma característica da universalização do sistema (MARX; ENGELS, 2007).

Tal cisão, tem implicações diretas na compreensão do gênero humano e das particularidades que residem no curso da história, pois, ao tornamos autônomas as ideias, considera-se que não há nenhuma relação entre as condições da produção, os produtores dessas ideias e os seus fundamentos (MARX; ENGELS, 2007).

O que se observa é que o estranhamento opera uma distorção própria da estrutura capitalista para a sua manutenção, ocultando entender que não há uma abstração/cisão entre o agir e pensar. Isso porque,

O indivíduo é o ser social. Sua manifestação de vida - mesmo que ele também não aparece na forma imediata de uma manifestação comunitária de vida, realizada simultaneamente com outros - é por isso, uma externação e confirmação da vida social. A vida individual e a vida genérica do homem não são diversas, por mais que também - e isto necessaria- 
mente - o modo de existência da vida individual seja um modo mais particular ou mais universal da vida genérica, ou quanto mais a vida genérica seja uma vida individual mais particular ou universal. Como consciência genérica o homem confirma sua vida social real e apenas repete no pensar sua existência efetiva, tal como, inversamente, o ser genérico se confirma na consciência genérica, e é, em sua universalidade como ser perante em si (MARX, 2010, p. 107).

Assim, a partir da teoria marxiana, identificamos a ideologia como sendo parte constitutiva do estranhamento do homem consigo, com o objeto, com os outros homens e com a natureza e que se forja no sistema capitalista, possibilitando, desta feita, a produção e perpetuação desta sociabilidade (MARX, 2008, 2008b, 2010, 2015; MARX; ENGELS, 2007). Sendo, portanto, um complexo dos complexos, que, nas relações sociais e na singularidade do ser social, vai operar uma ocultação do real concreto próprio do modo de produção e reprodução capitalista. Isso não significa que as formas como os homens se relacionam sejam falsas ou ilusórias, mas que são produtos e reproduções de uma estrutura que, ao passo que se complexifica, aprofunda uma sociabilidade que não cria uma igualdade substantiva. Ao contrário, agrava a segregação social e racial, as desigualdades de classes e regionais, mantendo oculta as contradições e violências que este sistema produz.

Desta feita, entendendo que as relações sociais se constituem enquanto determinações materiais que exigem mediações de diversas ordens, quando analisamos a formação social brasileira e como as classes se relacionam, observamos a prevalência de uma ideologia que tem raízes nos três elementos basilares do modo de dominação burguesa brasileira: acumulação de renda, prestígio e poder. Ou seja:

$1^{\circ}$ ) a capacidade da iniciativa privada interna de captar as irradiações econômicas das grandes corporações, das nações capitalistas hegemônicas e do mercado capitalista mundial; $2^{\circ}$ ) a capacidade de mobilização social e política da burguesia como classe possuidora e privilegiada; $3^{\circ}$ ) a possibilidade de converter o Estado em eixo político de recomposição do poder econômico, social e político da burguesia, estabelecendo-se uma conexão direta entre dominação de classe, concentração de poder político de classe e livre utilização., pela burguesia do poder político estatal daí resultante (FERNANDES, 2005, p. 309).

Estes três elementos, conforme Fernandes (2005), expressarão as características materiais e espirituais com as quais a burguesia estabelecerá sua relação de dominação e recomposição do poder econômico, social e político no 
Brasil, reproduzindo uma ordem social particular, que acompanha "[...] os dinamismos econômicos e os ritmos históricos que as nações capitalistas hegemônicas transferiram para a sociedade brasileira" (FERNANDES, 2005, p. 308).

Assim, ao mesmo tempo em que a dominação burguesa é "[...] reajustada, estrutural e funcionalmente, às exigências econômicas das situações emergentes esta produção e reprodução da ideologia de prestígio, poder e renda oferece para a dominação burguesa brasileira a possibilidade de bloquear as forças antagônicas organizadas, de contestação política revolucionária" (FERNANDES, 2005, p. 308).

Isso porque,

As ideias da classe dominante são, em cada época, as ideias dominantes, isto é, a classe que é a força material dominante da sociedade é, ao mesmo tempo, sua força espiritual dominante. A classe que tem à sua disposição os meios da produção material dispõe também dos meios da produção espiritual. As ideias dominantes não são nada mais do que a expressão ideal das relações materiais dominantes, são as relações materiais dominantes apreendidas como ideais; portanto, são a expressão das relações que fazem de uma classe a classe dominante, são as ideias de sua dominação (MARX; ENGELS, 2007, p. 47, grifo do autor).

Dentre as características que são possíveis de observar na ideologia burguesa brasileira, temos a reprodução de um homem burguês alicerçado na figura do senhor rural, que reproduz a violência, especialmente contra negros e povos originários; concentração de renda, com destaque para os latifúndios agrários; mandonismo; populismo; moralidade cristã; prestígio familiar; e avesso a democracia, ainda que esta esteja nos limites da própria ordem burguesa, em que o lema central será: pátria ${ }^{2}$, família e Deus.

A ideologia do prestígio, poder e renda molda a burguesia no Brasil a partir da mentalidade herdada do senhor rural e manifesta-se em níveis variados, nos mais diversos espaços de sociabilidade. O prestígio através do reconhecimento da importância da pessoa e/ou de sua capacidade individual mérito -, seja em um grupo localizado ou ampliado, ainda que este reconhecimento seja passageiro; o poder se expressará quando a tomada de decisões precisa passar pelo seu aval, sendo atribuído um certo controle na cadeia de comando, ainda que este poder seja limitado; a renda, que diferentemente das frações burguesas que detém uma alta concentração de renda, para o sujeito da

\footnotetext{
${ }^{2}$ Conforme Fernandes (2005), os momentos revolucionários, dentre eles a contrarrevolução burguesa de 1964, foram marcados pela ausência de um projeto de nação. Portanto, o termo pátria que é propagado é um projeto de aprofundamento da dependência ao capital internacional.
} 
classe trabalhadora, a mobilidade vertical limitada ${ }^{3}$ dentro dos espaços de trabalho ou as oportunidades de "empreender" de forma individual, se apresenta como possibilidade de enriquecimento no mesmo patamar do burguês. Ou seja, na lógica capitalista, "vende-se" um sonho de possibilidade para o trabalhador que, em última instância, tem como modelo ideal elementos estruturantes herdados da mentalidade do senhor rural. A ideologia do prestígio, poder e renda é a expressão, no capitalismo dependente, da condição colonial permanente, conforme examinado no capítulo dois.

Considerando que os elementos estruturantes são readaptados, mas não rompidos, a figura do senhor rural, na atualidade, sofrerá um reajuste combinado com a ideologia neoliberal capitalista hegemônica, trazendo à tona um tipo de homem, em especial, de trabalhador. Essa ideologia reproduzirá, de forma combinada, tanto as características mais amplas do estranhamento (e suas complexificações) inerentes ao capitalismo, como aquelas constitutivas do capitalismo dependente: a atomização do indivíduo, o não reconhecimento enquanto classe, o empresário/patrão de si e a desumanização do ser social, quanto as particulares justificativas para o não reconhecimento da segregação regional e étnico-racial ${ }^{4}$, a dificuldade de aderência a pautas de uma democracia de participação ampliada - ainda que dentro da ordem burguesa -, a perpetuação de famílias nos espaços de poder e comando - como temos no judiciário e no legislativo $^{5}$-, a defesa de uma ordem tradicional - que na verdade implica na defesa dos interesses privados das frações burguesas -, a reprodução de mandonismo em razão de algum cargo e/ou função e/ou diplomação e/ou "família" - como se isso lhe desse liberdade para praticar atos ilícitos e contravenções sem ser julgado $^{6}$-, táticas populistas de apassivamento da classe trabalhadora frente aos ataques de seus direitos, a presença ainda marcante do voto de cabresto e a relativização do trabalho escravo na atualidade, dentre outros.

Como podemos observar, a ideologia das classes dominantes não se trata apenas de um elemento que reproduz uma determinada forma de sociabili-

\footnotetext{
${ }^{3}$ Partimos do entendimento que há uma mudança na posição hierárquica do cargo, contudo, esta alteração não se converte, na maioria das vezes, na possibilidade de alterar a condição de assalariamento do trabalhador, ou seja, de classe social.

${ }^{4}$ Há uma relativização e tentativa de apaziguamento do racismo estrutural com o mito da democracia racial e/ou miscigenação, que também contaram com apoio de produções teóricas no campo da Sociologia.

${ }^{5}$ Exemplo disso temos a bancada "BBB" no Congresso Nacional: "Bancada da Bala, Boi e Bíblia", que representa os interesses típicos da burguesia brasileira com traços de senhor rural.

${ }^{6}$ Vulgarmente conhecida como "carteirada" ou "você sabe com quem está falando?".
} 
dade para atender um determinado modo de produção, trata-se de um modo de produção que consegue se perpetuar porque produz e reproduz uma determinada sociabilidade. Isso não significa que não existam organizações e lutas da classe trabalhadora para se contrapor a este projeto. Também não é correto dizer que exista um apassivamento tamanho que impeça qualquer alteração desta dependência, segregação, violência e desigualdade de classes.

O que estamos destacando aqui é que, nos mais diversos níveis de complexidade, a manutenção de um determinado projeto de sociabilidade precisa também, nos espaços de sociabilidade, reproduzir-se e ser introjetado no sujeito singular. Ainda que posteriormente o sujeito reveja determinados pré-conceitos, há na estrutura das relações sociais capitalistas do Brasil, uma ideologia que também é reproduzida no conjunto da classe trabalhadora. O que denota que a ideologia, tal qual Marx $(2008 ; 2010 ; 2015)$ já identificava naquele momento histórico enquanto elemento do estranhamento, é parte constitutiva do modo de produção capitalista, sendo expressa, em cada formação social e tempo histórico, com características particulares, mediadas pela organização da divisão internacional do trabalho entre os países imperialistas e dependentes.

\section{PRODUÇÃO E REPRODUÇÃO DA IDEOLOGIA BURGUESA NA UNIVERSIDADE PÚBLICA}

Partindo do pressuposto de que "[...] a universidade não é um mundo à parte no cenário brasileiro: ela [...] extrai o caráter do seu subdesenvolvimento da própria estrutura e dinâmica da sociedade de classes sob o capitalismo dependente" (FERNANDES, 1975, p. 196), trataremos neste item da análise de alguns aspectos da produção e reprodução da ideologia burguesa na Universidade Pública.

Conforme Fernandes (1975), as primeiras instituições de ensino superior que surgem no Brasil são as Escolas Superiores. Tais Escolas buscavam atender os interesses das frações dominantes existentes e que emergiam - especialmente as classes médias -, com o objetivo de aumentar a sua participação nas estruturas de poder e decisão (FERNANDES, 1975; MINTO, 2014). Ou seja, elas "[...] organizaram a vida intelectual como parte de uma 'situação colonial crônica’ de dependência cultural” (FERNANDES, 1975, p. 160).

Ao longo do processo histórico de organização e reorganização das classes no Brasil, as instituições de ensino acompanharam as demandas das forças políticas em disputa. Especificamente as instituições de ensino superior, 
passaram por reformas, com destaque para as operadas nas décadas de $1930 \mathrm{e}$ 1940, 1960, 1990, 2000 e as em curso na atualidade, conforme examinado nos capítulos anteriores.

Apesar de localizarmos períodos específicos que, inclusive, culminaram no reordenamento dos modelos institucionais anteriores, como a criação de instituições de ensino superior sob o modelo universidade, a reconfiguração do modelo de escolas superiores isoladas não se fez acompanhada de uma ruptura radical com as estruturas arcaicas mas, combinou os elementos arcaicos com os tempos modernos (FERNANDES, 1975).

Isso significa entender que, o que se viu no Brasil não foram reformas universitárias, mas contrarreformas universitárias que acompanharam o dinamismo e a participação do país de forma dependente em relação ao exterior, nos marcos da heteronomia cultural associada à inserção capitalista dependente do Brasil na economia mundial. Pois, as alterações, ajustes ou correções, ainda que tenham permitido avançar no atendimento de demandas dos movimentos sociais organizados pela classe trabalhadora, as "[...] exigências educacionais e culturais do mundo urbano-industrial ou simplesmente urbano brasileiro" (FERNANDES, 1975, p. 164), não empreenderam em uma reorganização que incorporasse, de fato, um modelo de universidade integrada e multifuncional capaz de atender o "[...] papel histórico que ela deve ter como fonte de negação e de superação da dependência cultural e do subdesenvolvimento educacional" (FERNANDES, 1975, p. 165).

Assim, entendendo que o padrão compósito de hegemonia burguesa e de transformação social no Brasil ${ }^{7}$ se mantém presente até os dias de hoje, a produção e reprodução da ideologia burguesa na Universidade Pública se fará acompanhada pelo reordenamento do sistema capitalista por meio das orientações dos organismos internacionais, a partir das exigências da reestruturação produtiva em um contexto de acumulação flexível financeirizada e de contrarreforma do Estado (BEHRING, 2008; HARVEY, 2012, 2014; SAKURADA, 2018).

Compatibilizando as orientações do Consenso de Washington, Banco Mundial, Declaração de Bolonha, Organização Mundial do Comércio e Organização Internacional do Trabalho (SGUISSARDI, 2006; LIMA, 2007; SAKURADA, 2018) com as particularidades do capitalismo no Brasil, as contrarreformas que são realizadas promovem, não apenas ataques contundentes no que diz

${ }^{7}$ Ver Capítulos 2 e 7 deste livro. 
respeito ao financiamento estatal público para manutenção e ampliação da educação presencial nas universidades públicas, mas realizam a expansão acelerada do setor privado de educação superior, com destaque para o ensino a distância, o repasse de verba pública por meio de programas de financiamento de estudos, como o Fundo de Financiamento Estudantil (FIES), e pelo estímulo dos fundos patrimoniais, que serão examinados nos próximos capítulos.

A contrarreforma da Educação Superior também precisou contar com o artifício da disseminação de uma ideologia que consolidasse, tanto os elementos estruturantes do capitalismo dependente, como atendesse os reordenamentos atuais do sistema capitalista. Esse processo se deu a partir de um conjunto de ações conduzidas nas décadas de 1990 e no início do novo século, a saber: (i) a ampliação da lógica da produtividade, monitorada por meio das agências de fomento de pesquisas; (ii) os requisitos para progressões funcionais dos docentes; (iii) a captação de recursos por meio de parcerias público-privadas; (iv) o privilegiamento das atividades de ensino em contraposição a integralização entre ensino, pesquisa e extensão; (v) a autorização para ofertar parte da carga horária de cursos presenciais na modalidade à distância; (vi) a flexibilização curricular, com vistas ao aligeiramento da formação profissional; (vii) a não reposição ou ampliação de concursos públicos para servidores técnicos e docentes que atendam as demandas dos $\operatorname{cursos}^{8}$; (viii) a reorganização das carreiras, com estímulo à contratação precarizada de servidores técnico-administrativos e docentes; (ix) o credenciamento e descredenciamento de cursos de graduação condicionado pela avaliação do curso no Exame Nacional de Desempenho de Estudantes (ENADE); (x) o orçamento universitário atrelado a chamada "taxa de sucesso" anual de formandos, dentre outros.

Se por um lado, a ideologia neoliberal operou no avanço da mercantilização da educação, criando novas estratégias dentro das Universidades Públicas para a conformação de um projeto de educação que visa atender as demandas imediatas de certificação em massa e da mercantilização da educação, compatíveis com as exigências de organismos internacionais para a participação do Brasil na divisão internacional do trabalho, por outro, ela recompôs, no interior da Universidade Pública os elementos estruturais de ideologia burguesa moldada a partir do tripé concentração de renda, prestígio e poder.

\footnotetext{
${ }^{8}$ Destacamos a não reposição de vagas ocasionadas por aposentadoria, morte ou exoneração. So bre a ampliação, destacamos aqueles cursos que foram criados ou foram objeto de ampliação em decorrência do Programa de Apoio a Planos de Reestruturação e Expansão das Universidades Federais (REUNI).
} 
E isso é observável, por exemplo, com a prevalência, até os tempos atuais, do termo "cátedra", que é reproduzido nos espaços universitários como forma de expressar tempo de antiguidade de um docente ou sua manutenção em determinada disciplina. Também observamos o termo sendo empregado como "autonomia de cátedra". Ainda que o termo, na maioria das vezes, seja utilizado para defender a autonomia docente perante imposições de silenciamento, controle ou censura, a persistência do termo "cátedra", quando analisado a partir das estruturas ideológicas do capitalismo dependente brasileiro, denota uma relação com os elementos ideológicos de poder e prestígio que o mesmo carrega, desde a gênese e desenvolvimento das universidades no país, conforme analisava Florestan Fernandes (1975).

Além desse termo, observamos também a não ruptura com as formas tradicionais de prestígio e de poder no que diz respeito a carreira docente. Ainda que a Lei n. 12.863/2013 (BRASIL, 2013) tenha incorporado o cargo de Titular $^{9}$, a reorganização da carreira, somado aos requisitos de mérito de produtividade individual, não corrigiu as discrepâncias quanto as possibilidades concretas de docentes alcançarem esta classe dentro da carreira, reproduzindo o aspecto de prestígio e poder.

Outra característica ideológica que se faz presente diz respeito a construção e execução coletiva de projeto político pedagógico nos cursos, que expressam um projeto de formação profissional. Assim como nos demais espaços de discussão e deliberação, faz parte do jogo democrático dissensos e consensos, contudo, o que observamos é que a autonomia docente, em alguns casos, é tomada como liberdade e poder para, inclusive, se contrapor as decisões coletivas e o projeto político-pedagógico do curso, não assegurando, desta forma, precisão quanto ao conteúdo que será desenvolvido ao longo do processo formativo (SAKURADA, 2018).

A própria organização curricular distribuída por disciplinas para cada período específico da formação também demonstra a presença do aspecto ideológico. Não negamos que os conteúdos precisam ser organizados e acompanhados de uma processualidade que seja acumulativa. O que chamamos atenção é na incipiência de espaços de debates entre os docentes que trabalham com estudantes do mesmo período.

É comum que docentes relatem, de forma isolada, dificuldades que, em alguma medida, também estejam aparecendo em outras disciplinas nas quais o

\footnotetext{
9 Antes desta Lei, para que um docente pudesse alcançar o cargo de titular era necessário ser aprovado em um concurso público específico para o cargo, mesmo sendo já docente da Universidade.
} 
estudante encontra-se vinculado no semestre. Ao serem, consciente ou não conscientemente, "empurrados" para uma individualização da responsabilidade no processo formativo, o que verificamos é a atomização dos conteúdos, reproduzindo aspectos da ideologia em curso. Dentre as causas podemos destacar a sobrecarga de trabalho (acúmulo de funções e atividades), ausência de materiais e equipamentos adequados para desempenhar suas atividades laborais na unidade, fazendo com que o docente precise utilizar o espaço privado de sua residência ou outro espaço institucional, diminuindo a frequência de momentos de encontros coletivos ${ }^{10}$.

Cumpre destacar que, a reprodução ideológica burguesa, e consequentemente sua produção, não é um elemento que comparece, em níveis variados e complexos, apenas no corpo docente. Ela também se faz presente nos demais sujeitos que pertencem a comunidade acadêmica. Nos espaços administrativos e organizativos das Universidades Públicas é possível identificar em alguns setores a reprodução do prestígio e do poder. É comum, dentro das repartições, que determinadas decisões que incidem diretamente na vida de terceiros esteja concentrada em pessoa específica, independente desta ser docente ou técnico.

No caso dos estudantes, a reprodução da ideologia é observada pelo "sucesso" em ingressar em uma Universidade Pública, conferindo um prestígio perante terceiros. Outro exemplo é a escolha do curso. Ainda que prevaleça na escolha do curso a afinidade singular e individual do estudante, em alguns casos, esta escolha também vem acompanhada pelo desejo de prestígio, poder e renda que a carreira ${ }^{11}$ pode proporcionar. Dentro do ambiente universitário, temos, também, a participação em determinados grupos (de estudos e/ou pesquisa e/ou extensão), que reproduz um ideário de prestígio e, em certa medida, de poder em contraposição aos demais estudantes, bem como a mensuração de prestígio por meio do chamado Coeficiente de Rendimento (CR).

\section{CONSIDERAÇÕES FINAIS}

A partir da análise sobre ideologia e sua expressão nas relações sociais capitalistas dependentes, particularmente na sociedade brasileira, o que pode-

\footnotetext{
${ }^{10}$ Em alguns casos, esses momentos de encontros coletivos ocorrem apenas nos espaços de reuniões deliberativas, como por exemplo Colegiados de Cursos e Plenárias Departamentais.

${ }^{11}$ É fato que, determinadas carreiras, no imaginário social ainda ocupam o status elitista, como é o caso do médico, advogado e engenheiro. Contudo, o que observamos é que, mesmo com a ampliação do ingresso dos filhos da classe trabalhadora nas instituições de ensino superior, a concentração de estudantes das frações da classe média e alta ainda persiste nestes cursos.
} 
mos observar é que, a Universidade Pública não está descolada da realidade que forma e conforma a sociedade brasileira. Cumpre destacar que, é fato que não cabe exclusivamente a esta comunidade o papel de romper com a ordem vigente. Contudo, na medida que a ideologia burguesa ainda é reproduzida na Universidade Pública de forma explícita ou não pelos sujeitos políticos que lhe dão vida, persistirá a reprodução da ideologia burguesa neste espaço por meio da formação de novos sujeitos históricos, caso o enfrentamento desta ideologia do prestígio, poder e renda não seja realizado.

Ainda que mudar a universidade exija transformar a sociedade, ou seja, realizar uma ruptura radical com o projeto de sociabilidade atual, concordamos com Fernandes (1975, p. 159) quando diz: "A destruição envolve uma reposição: os homens não destroem socialmente senão aquilo que eles querem reconstruir".

Por esta razão, construir um projeto que atenda os reais interesses materiais e humanos de uma sociedade independente e emancipada, exige de nós a ousadia de reconstruir, sob novas bases, a Universidade Pública.

\section{REFERÊNCIAS}

BEHRING, E. R. Brasil em contrarreforma. São Paulo: Cortez, 2008.

BRASIL. PRESIDÊNCIA DA REPÚBLICA. LEI No 12.863, DE 24 DE SETEMBRO DE 2013. Brasília. Disponível em < http://www.planalto.gov.br/ ccivil 03/ Ato2011-2014/2013/Lei/L12863.htm >. Acesso em: 9 fev.2021

EAGLETON, T. Ideologia: uma introdução. São Paulo: Boitempo, 2019.

FERNANDES, F. Universidade brasileira: reforma ou revolução? São Paulo: Alfa-Omega, 1975.

A revolução burguesa no Brasil: ensaios de interpretação sociológica. São Paulo: Globo, 2005.

HARVEY, D. Condição Pós-Moderna. São Paulo: Edições Loyola, 2012.

. O Neoliberalismo: história e implicações. São Paulo: Edições Loyola, 2014. 
IASI, M. Ensaio sobre Consciência e Emancipação. São Paulo: Expressão Popular, 2011.

LIMA, K. Contra-reforma na educação superior: de FHC a Lula. São Paulo: Xamã, 2007.

MARX, K. Contribuição à Crítica da Economia Política. São Paulo: Expressão Popular, 2008a.

O 18 de Brumário de Luís Bonaparte. São Paulo: Martin Claret, 2008b.

. Manuscritos econômico-filosóficos. São Paulo: Boitempo, 2010.

O Capital: crítica da economia política: Livro I - o processo de produção do capital. São Paulo: Boitempo Editora, 2015.

MARX, K; ENGELS, F. A Ideologia Alemã. São Paulo: Boitempo, 2007.

MÉSZÁROS, I. A Educação Para Além do Capital. São Paulo: Boitempo Editora, 2008.

MINTO, L. W. A Educação da "Miséria": Particularidade Capitalista e Educação Superior no Brasil. São Paulo: Outras Expressões, 2014.

SAKURADA, P. K. C. Serviço Social e formação profissional: um estudo sobre o ensino dos Fundamentos do Trabalho Profissional em Serviço Social no Brasil. 2018. 244 f. Tese (Doutorado em Serviço Social) - Escola de Serviço Social, Universidade Federal do Rio de Janeiro, Rio de Janeiro, 2018.

SGUISSARDI, V. Reforma universitária no Brasil - 1995/2006: precária trajetória e incerto futuro. Campinas. Revista Educação e Sociedade, v. 27, n. 96, p. 1021-1056, out. 2006.

WILLIAMS, R. Palavras-Chave: um vocabulário de cultura e sociedade. São Paulo: Boitempo, 2007. 